\title{
Improved Open Photoacoustic Helmholtz Cell
}

\author{
Tomasz Starecki · Antonina Geras
}

Received: 11 April 2013 / Accepted: 19 June 2013 / Published online: 16 July 2013

(C) The Author(s) 2013. This article is published with open access at Springerlink.com

\begin{abstract}
This paper presents the design of an open photoacoustic Helmholtz cell in which high acoustic volumes with quarter-wave ducts act as high-impedance separators between the main Helmholtz cell structure and the exterior. As a result, penetration of the external acoustic noise into the cell was substantially reduced in comparison to earlier open Helmholtz cell designs. Although the presented cell is not windowless, the photoacoustic background signal resulting from the absorption of the light by the windows is significantly lower in comparison to standard Helmholtz cells. Such an effect was obtained by locating the windows not at the relatively small sample cavity, but at the acoustic buffers, for which the volumes are two orders of magnitude higher. The proposed cell is dedicated for gas or liquid measurements, and its design allows for constant flow of the fluid. Hence, it can be used in continuous, real-time photoacoustic measurements.
\end{abstract}

Keywords Acoustic buffers - External acoustic noise attenuation - Helmholtz resonator · Open photoacoustic cell

\section{Introduction}

The amplitude of the photoacoustic signal depends on many factors, but in particular it varies inversely to the light modulation frequency, $f$, and volume of the cell, $V$, and is proportional to the quality factor, $Q$, of the cell (if the light is modulated with a frequency at which the acoustic resonance of the cell occurs) [1]:

T. Starecki $(\varangle) \cdot$ A. Geras

Institute of Electronic Systems, Warsaw University of Technology,

Nowowiejska 15/19, 00-665 Warsaw, Poland

e-mail: t.starecki@ise.pw.edu.pl 


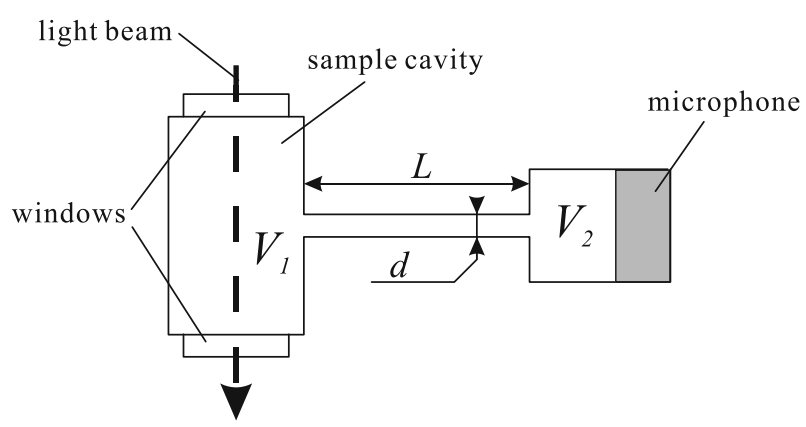

Fig. 1 Sketch of a simple photoacoustic Helmholtz cell for gas measurements

$$
A \propto \frac{Q}{f V}
$$

A structure commonly applied in photoacoustic cell designs is a Helmholtz resonator, which typically consists of two cavities connected with a duct (Fig. 1). The Helmholtz resonator allows for preserving a small cell volume (a few $\mathrm{cm}^{3}$ or less [2-4]) even if $1 / 2^{\prime \prime}(1.27 \mathrm{~cm})$ or $1^{\prime \prime}(2.54 \mathrm{~cm})$ microphones are used. The resonance of the cell can be used for amplification of the photoacoustic signal and its frequency $f_{\text {res }}$ can be kept low, as it is not proportional to linear dimensions, but depends on several mechanical properties of the resonator $[1,5]$ :

$$
f_{\mathrm{res}} \approx \frac{v d}{4 \pi} \sqrt{\frac{\pi}{L} \frac{V_{1}+V_{2}}{V_{1} V_{2}}}
$$

where $V_{1}, V_{2}$ are the cavity volumes, $L$ is the duct length, $d$ is the duct diameter, and $v$ is the sound velocity in the fluid inside the cell.

It is essential that the resonance frequency of the Helmholtz resonator depends on the duct length and diameter. Hence, it can be easily adjusted within a relatively wide range without affecting the total volume of the cell.

Photoacoustic Helmholtz cells are most often used in the investigation of solid samples [1]. In such a case one of the cavities is usually used as a sample container, while the other holds the detector-typically a microphone. The exchange of a solid sample usually requires user interaction. Quite often partial disassembly of the cell (e.g., removal of the sample cavity window) is needed. In the case of investigation of liquids or gases, the photoacoustic cell is often equipped with an inlet and outlet on which valves are mounted [4,6-8]. Such a solution allows for automatic sample exchange. For the time of measurement the valves are closed, which substantially decreases penetration of the external acoustical noise into the cell and simultaneously keeps the cell sealed, so that the photoacoustically induced pressure changes will not deteriorate. However, some applications, e.g., monitoring of toxic or explosive substances, chemical reactions, etc., may require continuous measurements with a constant flow of the measured fluid through the cell. In such a case an open photoacoustic cell is more convenient. 


\section{Open Photoacoustic Helmholtz Cells}

The most common open photoacoustic cells are resonant cells in which the inlet and outlet are located in the nodes of the standing wave $[9,10]$. In the case of a Helmholtz cell, the resonance results from a piston-like pressure stimulation in the sample cavity produced by the photoacoustic effect which leads to alternate pressure changes in the cavities and a periodical flow of the gas or liquid filling the cell between the cavities. Certainly, there is no standing wave and no wave nodes in such a case, so that the approach to implementation of the cell openings must be different. There are very few open photoacoustic Helmholtz cells reported in the literature [11,12]. In the paper of Diószeghy et al. [11] the cell is just an uncoupled Helmholtz resonator, opened to the ambient (Fig. 2). In such a case, the exterior can be considered as one of the two cavities forming a resonator, which in turn means that any external acoustic noise will propagate to the microphone cavity and will be amplified by the cell resonance.

In the solution presented by Starecki [12], connection of the Helmholtz cell with the exterior is implemented with two coaxial channels (external ducts), which can be used as the inlet and outlet, allowing for flow of the gas or liquid that fills the cell (Fig. 3). As the light beam can be passed through the ducts, there is no need for windows, thus, a potential background photoacoustic signal resulting from absorp-

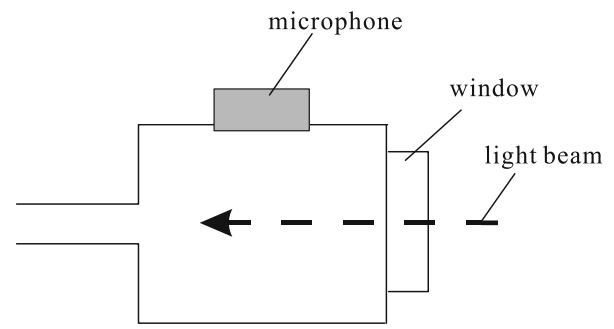

Fig. 2 Uncoupled Helmholtz resonator used as a photoacoustic cell [11]

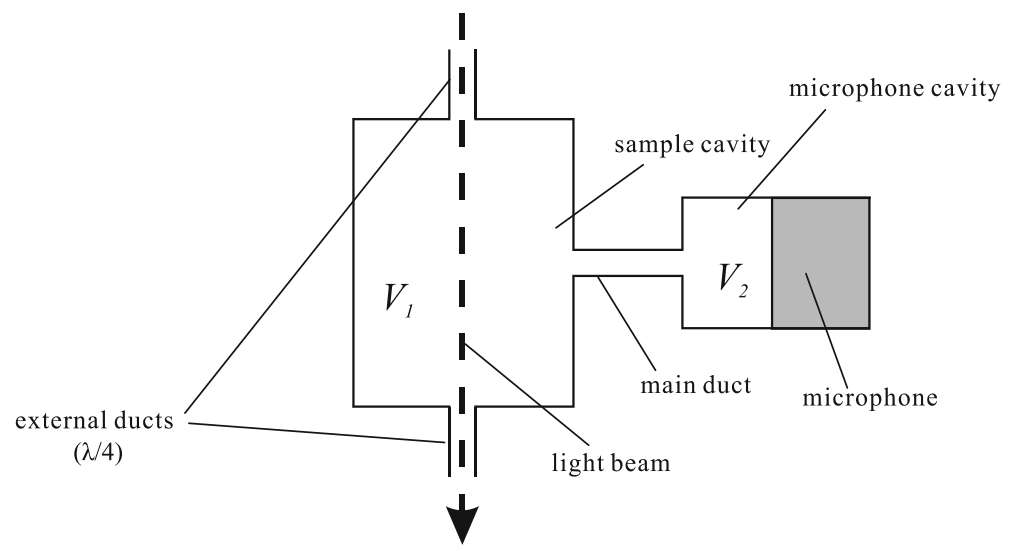

Fig. 3 Design of an open windowless photoacoustic Helmholtz cell [12] 
tion of the light by the windows is eliminated. Dimensions of the ducts are chosen in such a way that their acoustic impedance observed from the sample cavity is high. As a result, pressure changes produced by the photoacoustic effect are only slightly suppressed by the presence of these ducts. High acoustic impedance of the ducts can be obtained by setting their length to a quarter of the acoustic wave corresponding to the frequency of the light beam modulation. A duct of such a length should be treated as an acoustic transmission line, and the input impedance $Z_{\mathrm{i}}$ of a quarter-wave transmission line loaded on the other end with the impedance $Z_{\mathrm{o}}$ is

$$
Z_{\mathrm{i}}=\frac{Z_{\omega}^{2}}{Z_{\mathrm{o}}}
$$

where $Z_{\omega}$ is the characteristic impedance of the line. It can be easily noticed, that if $Z_{\mathrm{o}}$ is the acoustic impedance of the cell exterior (meaning that $Z_{\mathrm{o}}$ is low), then the impedance $Z_{i}$ of the duct observed from the sample cavity is high. As a result, frequency responses of the closed cell from Fig. 1 designed for operation at the Helmholtz resonance and of the corresponding open cell from Fig. 3 in which the length of the external ducts was appropriately adjusted are nearly identical within the frequency range close to the resonance (Fig. 4) [13]. Unfortunately, as the sample cavity volume $V_{1}$ is small, its acoustic impedance is definitely not low. Thus, due to Eq. 3, acoustic impedances of the external ducts observed from the exterior are relatively low. This in turn means that the external acoustic noise will easily penetrate such a cell, which is clearly visible in Fig. 4.

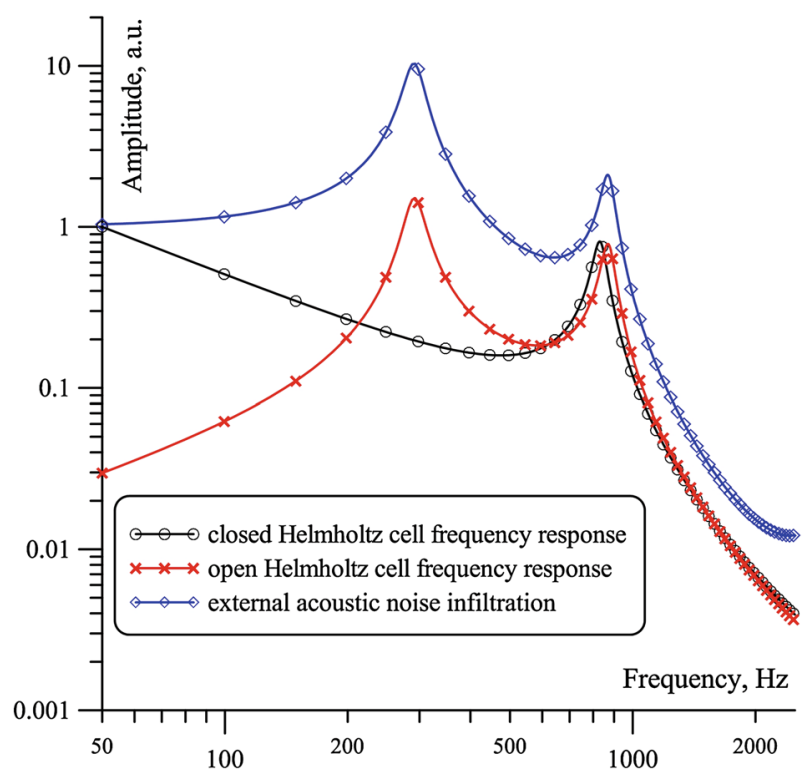

Fig. 4 Frequency responses of the cells shown in Figs. 1 and 3, and noise infiltration of the open Helmholtz cell from Fig. 3 [13] 


\section{Improved Open Helmholtz Cell Design}

Although the design presented in Fig. 3 has some advantages, it suffers from strong propagation of the external noise inside the cell, which makes its applications impractical. Attenuation of external noise can be substantially improved by means of acoustic buffers with quarter-wave ducts as shown in Fig. 5. If the buffers are of relatively high volume, their acoustic impedance can be considered as low. Thus, according to Eq. 3, the impedance of the external ducts observed from the exterior will be high. Similarly, the impedance of the internal ducts observed from the sample cavity will be high. As a result, infiltration of the external acoustic noise should be significantly reduced (in comparison to the cell design from Fig. 3), while the frequency response of the cell around the Helmholtz resonance created by the sample cavity, microphone cavity,

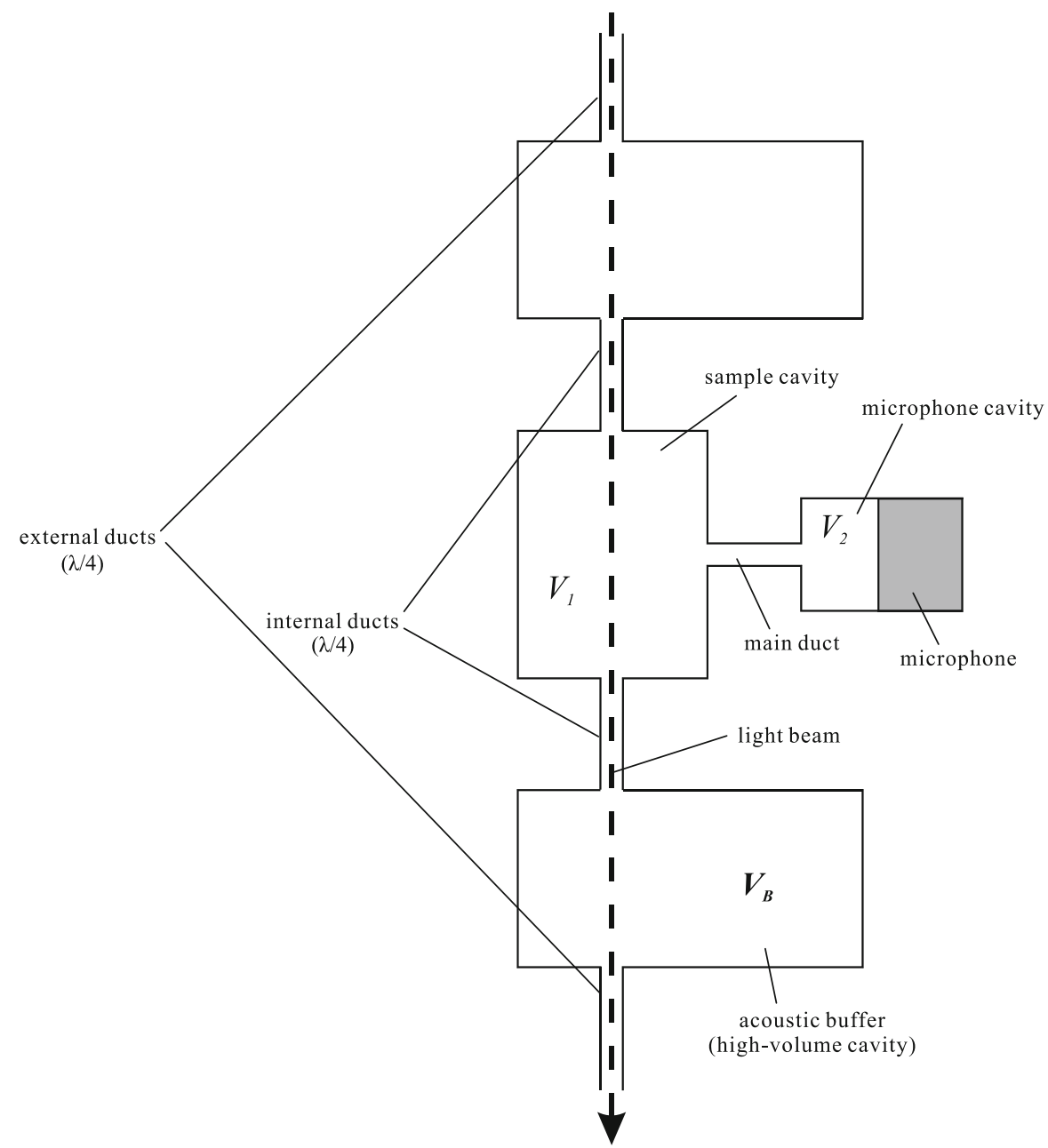

Fig. 5 Improved windowless photoacoustic Helmholtz cell 


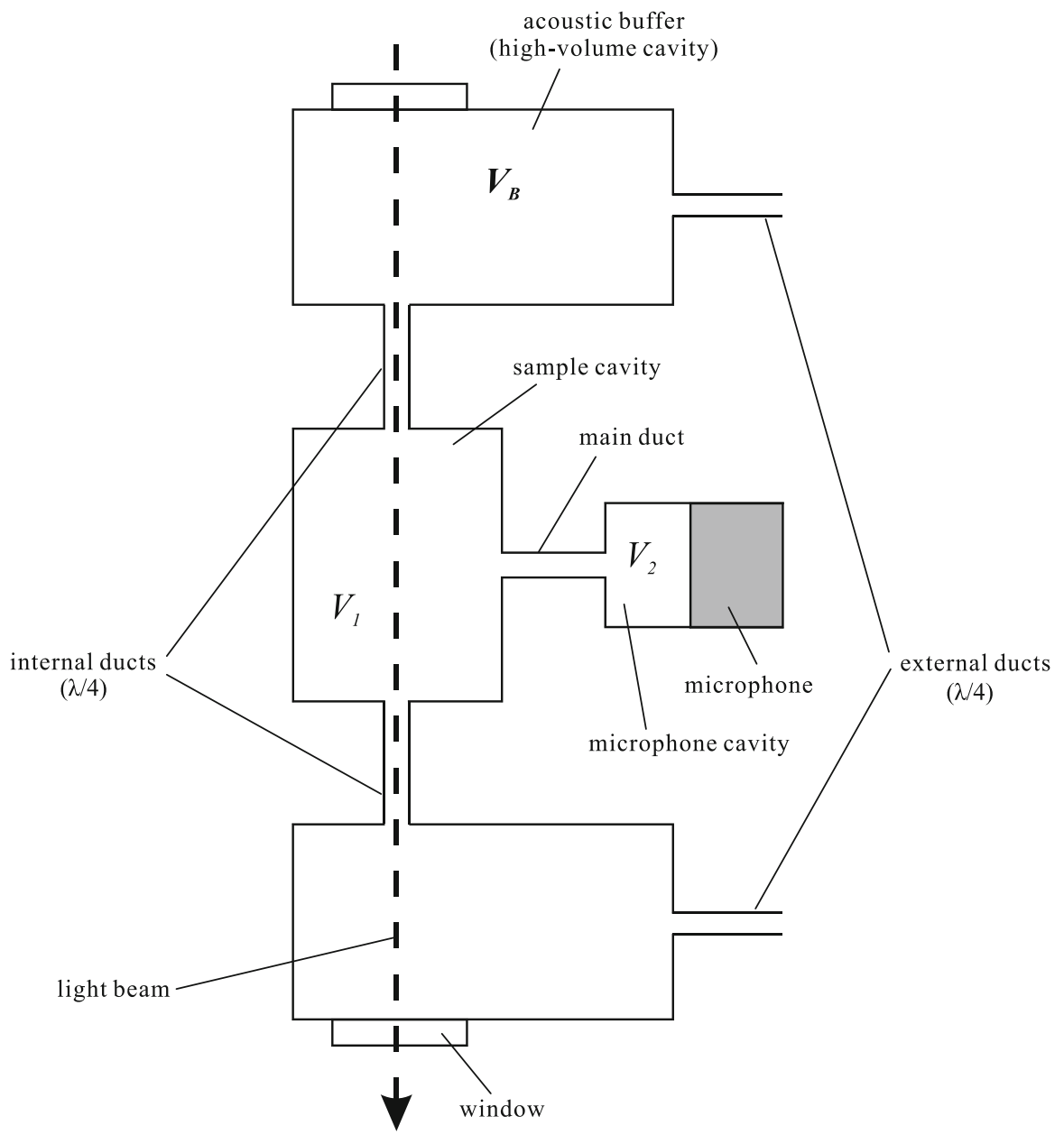

Fig. 6 Modified open photoacoustic Helmholtz cell

and the main duct should not change noticeably. If the internal and external ducts are coaxial, the light beam can be passed through them, similarly as in the case of the cell in Fig. 3, so that there will be no background signal produced by the absorption of light by the cell walls or windows. Unfortunately, due to the acoustic-wave-dependent dimensions, the optical path length in the cell increases with the frequency of light beam modulation $f_{\text {mod }}$. For example, if $f_{\text {mod }}=1 \mathrm{kHz}$, the corresponding acoustic wavelength in the air is approx. $35 \mathrm{~cm}$. In such a case the optical path length will be probably around $50 \mathrm{~cm}$ (four quarter-wave ducts plus the length of the sample cavity and two acoustic buffers). Taking into consideration that the diameters of the ducts should be rather small (typically not more than $3 \mathrm{~mm}$ ), high precision would be required from the manufacturing of such a cell, as well as from the light beam collimation and positioning. These requirements can be significantly lowered if the cell design is modified as in Fig. 6. In such a case high precision is needed on a twice shorter 


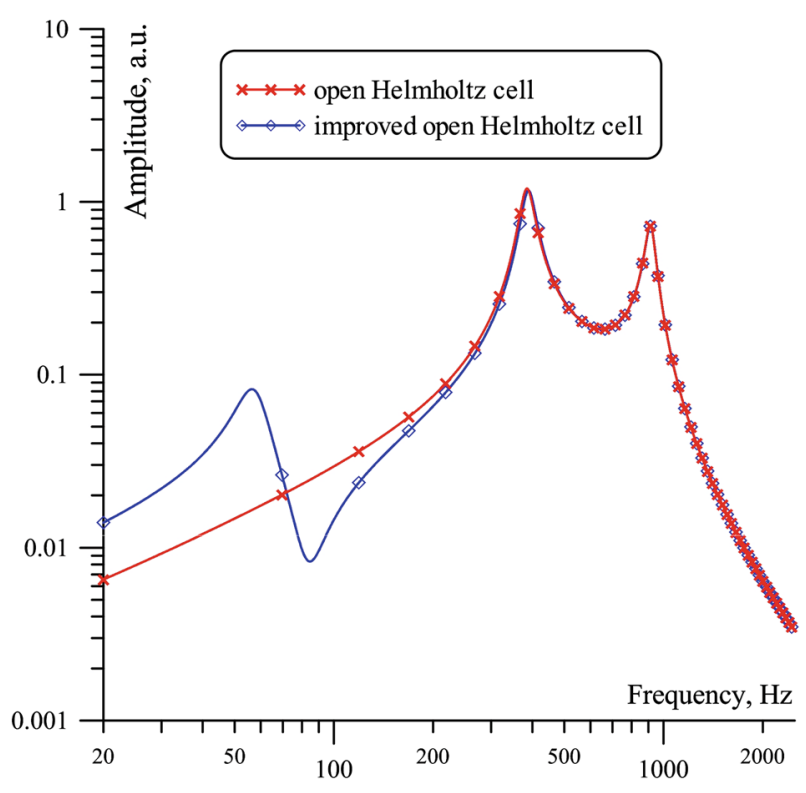

Fig. 7 Frequency responses of the open Helmholtz cells with structures shown in Figs. 3 and 6

distance (two quarter-wave ducts plus length of the sample cavity). The modified cell is equipped with windows, which will introduce a background photoacoustic signal due to parasitic absorption of the light beam. However, assuming that the sample cavity has a volume of a few $\mathrm{cm}^{3}$, while the volume of the buffers will be a few hundred $\mathrm{cm}^{3}$, and taking into consideration the relationship given by Eq. 1, the background signal resulting from such an absorption will be approximately $V_{\mathrm{B}} / V_{1} \approx 100$ times smaller in comparison to the corresponding background signal in the cell with the structure given in Fig. 1. An important advantage of the modified cell from Fig. 6 is that as the external ducts are no longer in the optical path; therefore, their diameters can be reduced. This should improve attenuation of the external acoustic noise, which in the case of an open cell is more likely to limit sensitivity of the setup, rather than the background signal from the window absorption.

Preliminary evaluation of the improved open cell properties was based on computer simulations. Models used in these simulations had been previously tested and proved to give very good results in modeling of photoacoustic cells with a multicavity structure [14]. Comparison of frequency responses and noise properties of the original (Fig. 3) and improved (Fig. 6) photoacoustic open Helmholtz cells are given in Figs. 7 and 8. In the evaluated improved cell, all the internal and external ducts had a length of $50 \mathrm{~mm}$, a diameter of $3 \mathrm{~mm}$, and the buffer volumes were $100 \mathrm{~cm}^{3}$. In both cells the sample cavity volume was $2 \mathrm{~cm}^{3}$, the microphone cavity volume was $1.5 \mathrm{~cm}^{3}$, and the main duct was $35 \mathrm{~mm}$ long and $3 \mathrm{~mm}$ in diameter. The frequency response of the improved cell has an additional Helmholtz resonance at a frequency of about $50 \mathrm{~Hz}$, resulting from interaction of the main part of the cell with the buffer volumes. At higher frequencies the impedance of the buffer volumes is low enough to make the 


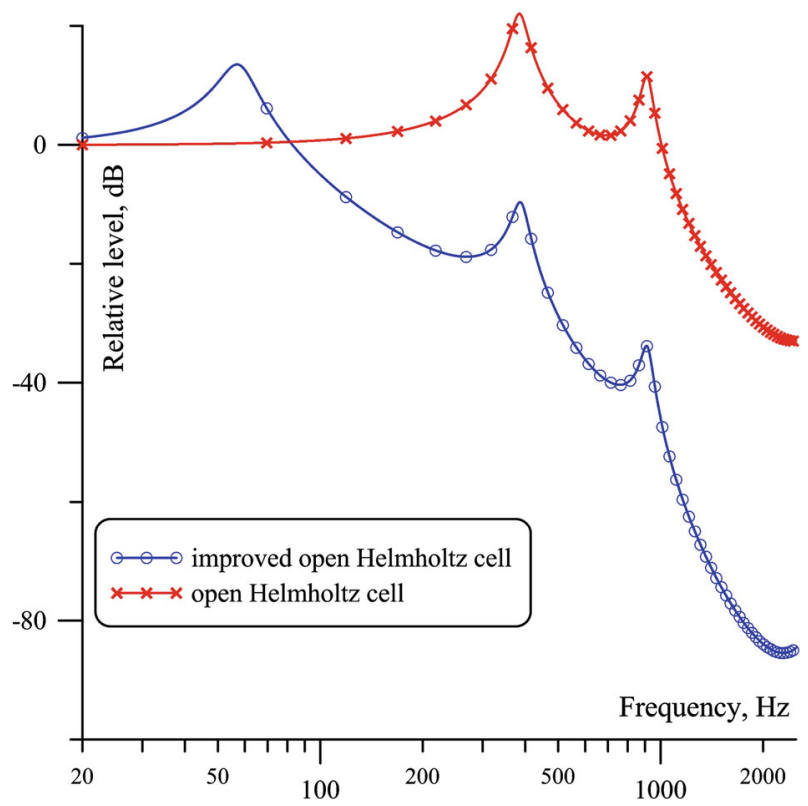

Fig. 8 Infiltration of the external acoustical noise in the open Helmholtz cells with structures shown in Figs. 3 and 6

frequency responses of both cells almost identical. It is also clearly visible that the buffers substantially improved attenuation of the external acoustic noise.

\section{Conclusions}

The presented improved open photoacoustic Helmholtz cell shows much lower susceptibility to external acoustic noise, which was the main drawback of the previous open cell design. Although the improved cell is not windowless, the photoacoustic background signal resulting from the absorption of light by the windows is also significantly reduced due to placing the windows at the acoustic buffers. The frequency response of the improved and previous cells in the range of frequencies around the primary resonance (Helmholtz resonance of the sample and microphone cavities) are virtually identical. In particular, the Q-factors and resonance frequencies have nearly the same values. Expected values of the external acoustic noise attenuation should be acceptable from the point of view of many practical applications.

Open Access This article is distributed under the terms of the Creative Commons Attribution License which permits any use, distribution, and reproduction in any medium, provided the original author(s) and the source are credited.

\section{References}

1. A. Miklós, P. Hess, Z. Bozóki, Rev. Sci. Instrum. 72, 1937 (2001)

2. E.M. Monahan Jr, A.W. Nolle, J. Appl. Phys. 48, 3519 (1977) 
3. D. Ducharme, A. Tessier, R.M. Leblanc, Rev. Sci. Instrum. 50, 1461 (1979)

4. J. Pelzl, K. Klein, O. Nordhaus, Appl. Opt. 21, 94 (1982)

5. N.C. Fernelius, Appl. Opt. 18, 1784 (1979)

6. R. Kästle, M.W. Sigrist, Appl. Phys. B 63, 389 (1996)

7. V. Zeninari, V.A. Kapitanov, D. Courtois, Yu.N. Ponomarev, Infrared Phys. Technol. 40, 1 (1999)

8. M.B. Pushkarsky, M.E. Webber, C.K.N. Patel, Appl. Phys. B 77, 381 (2003)

9. S. Schäfer, M. Mashni, J. Sneider, A. Miklós, P. Hess, H. Pitz, K.-U. Pleban, V. Ebert, Appl. Phys. B 66, $511(1998)$

10. S. Schilt, J.-P. Besson, L. Thévenaz, Appl. Phys. B 82, 319 (2006)

11. T. Diószeghy, A. Miklós, A. Keleman, A. Lórincz, J. Appl. Phys. 56, 2105 (1985)

12. T. Starecki, Acta Phys. Pol. A 114, 211 (2008)

13. T. Starecki, Acta Phys. Pol. A 114, 199 (2008)

14. T. Starecki, J. Acoust. Soc. Am. 122, 2118 (2007) 